\title{
May antihistone antibodies replace antinuclear antibodies (ANA) as a predictor of uveitis in Juvenile idiopathic arthritis? EB Nordal*1, NT Songstad ${ }^{2}$, B Straume ${ }^{3}$, L Berntson ${ }^{4}$ and M Rygg ${ }^{5}$
}

Address: ${ }^{1}$ Department of Pediatrics, University Hospital of North Norway and Institute of Community Medicine, University of Tromsø, Tromsø, Norway, ${ }^{2}$ Department of Pediatrics, University Hospital of North Norway, Troms $\emptyset$, Norway, ${ }^{3}$ Institute of Community Medicine, University of Tromsø, Tromsø, Norway, ${ }^{4}$ Department of Women's and Children's Health, Uppsala University Children's Hospital, Uppsala, Sweden and ${ }^{5}$ Department of Laboratory Medicine, Children's and Women's Health, Norwegian University of Science and Technology and Department of Pediatrics, St. Olavs Hospital, Trondheim, Norway

* Corresponding author

from $15^{\text {th }}$ Paediatric Rheumatology European Society (PreS) Congress London, UK. 14-17 September 2008

Published: 15 September 2008

Pediatric Rheumatology 2008, 6(Suppl I):P4 doi:I0.II86/I546-0096-6-SI-P4

This abstract is available from: http://www.ped-rheum.com/content/6/SI/P4

(C) 2008 Nordal et al; licensee BioMed Central Ltd.

\section{Background}

Antihistone antibodies (AHA) are an ANA subtype reported to be associated with uveitis in Juvenile idiopathic arthritis (JIA). Enzyme-linked immunoassays (EANA) are increasingly used as a more standardized alternative to the immunofluorescense method on Hep- 2 cells (IF-ANA). E-ANA, however, show no association with uveitis and should not be used in the diagnostic work-up of JIA.

\section{Materials and methods}

Sera of 100 children with JIA and 60 healthy children were analyzed for antihistone IgM/IgG (Pharmacia ELIA kit), for E-ANA and IF-ANA. Patients were recruited prospectively and followed at regular intervals from onset of disease in 1997-2004.

\section{Results}

Of the 100 children with JIA, 16 developed asymptomatic chronic uveitis; mean observation time was seven years. Antihistone $\operatorname{IgM} / \operatorname{IgG}>30 \mathrm{U} / \mathrm{ml}$ were found in six of the 100 children with JIA, four of whom developed uveitis, and in one of the controls. However, exploring lower cutoff levels of AHA, we found uveitis in 13 of 44 patients with AHA $>8 \mathrm{U} / \mathrm{ml}$. Analyses of predictors for uveitis show that young age at onset of arthritis, AHA $>8 \mathrm{U} / \mathrm{ml}$ and IF-ANA titer $>1 / 320$ carry significantly increased risk of developing uveitis. No significant increased risk is found for the oligoarthritis subtype, female gender, positive E-ANA and IF-ANA titer $>1 / 80$.

\section{Conclusion}

Antihistone IgM/IgG are significantly associated with uveitis in JIA children. AHA at a low cut-off level, show comparable test performance as IF-ANA, in predicting uveitis. As E-ANA replaces IF-ANA in many laboratories, further studies are needed to confirm the value of the AHA in risk stratification for uveitis screening. 